\title{
SICKLE CELL ANEMIA USING IMAGE DISSECTION
} TECHNIQUE

\author{
Ankit Mishra \\ Assistant Professor (ASET) \\ Dept. Of Electrical and Electronics \\ Amity University Chhattisgarh
}

\section{Abstract}

Sickle cell disorder (SCD) carries crescent shaped red blood cell in human body which causes chronic illness, anemia and shorter life span. To identify SCD we have used algorithmic approach to detect SCD using image dissection technique. This method is based on calculating the shape and size of red blood cell in axis. In this paper we also discuss the various existing techniques to identify SCD.

Keyword: Sickle Cell, RBC, Transducer

I.

INTRODUCTION

Sickle cell anemia is a major genetic disorder and transmissible disorder which associated to blood [1]. The rooted disorder of R.B.C.'S that due to the insufficiency of oxygen which reduce the cell and become sickle in shape. SCD affects more than 72000 Americans, primarily those of African heritance, but also those of Arabian, Asian, Caribbean, Indian, Mediterranean, and South and Central American ancestry [2]. The most common type of SCD'S are SS, SC and S beta Thalassemia. Other more scanty forms include SD-Punjab, SOArab, and S-Lepore and SE disease [3].

SCD is a permanent condition that may result in a serious health problem. Approximately 5\% of the world's population carries the trait for hemoglobin disorders, mainly SCD [4]. The sickle cell is a genetic ataxia due to endowment of the mutant gene from both, generally healthy parents, over 300000 babies with cruel hemoglobin disorder are born each year [5]. These conditions are most common in the tropical region. Due to the migration of humans this SCD dispersed in most of the countries [6].

As per the data, 300000 children were born in the Sub-Saharan African region, West-Indies and in South Asia region [7].To detect this SCD, various method and techniques are used. The most common technique is to count the sickle cell under microscope observation. This method is oldest and have prone to errors and miscalculations.

Most of the medical centers use the hematology analyzers which work on the electrical resistance principle. To overcome this old method many new medical devices are introduced. To get quick and easy result Image Dissection or Image Segmentation Technique is used. These techniques work on Image processing, Image filtering and electrical and electronic signals, whose values can be calculated with the standard algorithm and can be displayed in digital meters. 


\section{ROLE OF HEMOGLOBIN}

Hemoglobin is found in all red platelets and carries oxygen from the lungs to tissues and organs all through the body. Ordinary RBC is delicate, smooth, round and can move effectively through the body as show in figure 1. At the point when influenced by SCD the red platelets wind up unbending sticky and sickle-formed. This outcomes in intermittent preventing of platelets along these lines anticipating carriage of oxygen to tissues and organs.

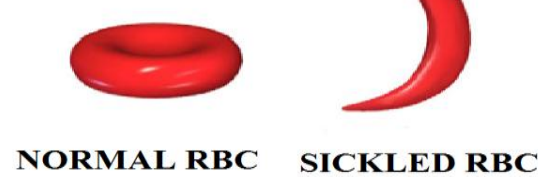

Fig (1): Normal RBC vs Sickled RBC

\section{SIGNS AND SYMPTOMS}

SCD symptoms are severe anemia, jaundice gallbladder stones, painful erection, failure of kidney and mental illness. Other than this this SCD also effects the flow of blood in human body due to which a constant pain is there in patient body [8].

\section{IMAGE DISSECTION}

Image dissection is the procedure of separating a digital image into variousfragments (sets of pixels, also known as super pixels) [9]. The aim of dissection is to streamline and/or change the representation of an image into something that is more significant and easier to investigate [10]. Image segmentation is usually used to detect objects and boundaries [11] (lines, curves, etc.) in images. Image segmentation is more accurate process than microscope method [12].

\section{LITERATURE SURVEY}

There have been many studies about sickle blood cell detection. One of them is the "Detection of Abnormal Blood Cells Using Image Processing Technique" by Malher Bhatt and ShashiProbha. In this study, the authors try to detect abnormal blood cells based on form factor and using image segmentation [13]. The form factor they used calculates the circularity shape of the cell, and if the cell not circular, it is counted as an abnormal cell. Another study, "Image Processing Based Abnormal Blood Cell Detection" by Deepika N. Patil and Uday P. Khot specified the threshold of each type of abnormal blood cell.

\section{SICKLE WATERSHED DETECTION TECHNIQUE}

Watershed transformation algorithm depends on region processing. A result of this algorithm is global segmentation with border closure and high accuracy [14]. It can attain one-pixel wide, closed, connected and exact place of the outline. The basic concept of this algorithm depends on visualizing grayscale images into the topographical representation which has minimal, catchment basins and watershed lines [15]. Watershed transformation algorithms have been used mostly in image processing. Some of the advantages of watershed transformation are simple, fast, can be parallelized and provide the complete internal structure of cell image [16].

\section{WATERSHED SEGMENTATION}

1. Input the Sullied and magnified human blood image and convert to binary image.

2. Image filtering algorithm applied to remove noise or unwanted spots.

3. Watershed segmentation applied on the image to separate the image from its background. 
4. The form factor is calculated for each cell. Form Factor defines as (4*pI*area/Perimeter2) [17]

\section{PROPOSED METHODOLOGY}

The proposed technique requires thoughtful planning of Algorithm, programming, and its execution [18]. This strategy requires a magnify lens, Ultrasonic Image Transducer, Microprocessor, analog to digital converter and display unit [19].

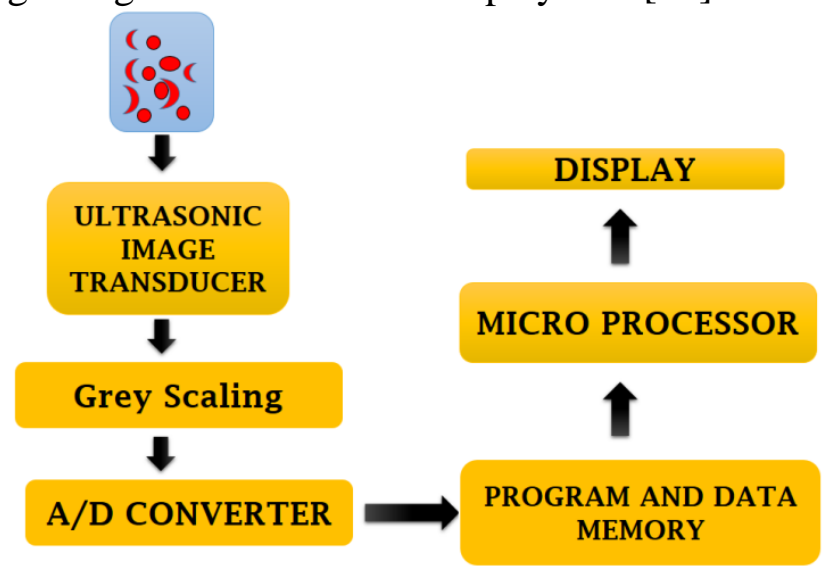

Fig (2): Proposed Structure of device design.

Ultrasonic image transducer in detection can be used to get image of blood cell. This ultrasonic image transducer works on ultrasound property [20]. This ultrasound can be detect by transducers which convert it to image form with the help of analog to digital [21].

\section{PIEZOELECTRIC CRYSTAL: AN IMPORTANT ULTRASONIC TRANSDUCER ELEMENT}

The piezoelectric crystal is one of the best commonly used component in the ultrasonic transducers [22]. It can be used as the both, transmitting as well as the receiving device, in the transducers. It is bounded within the casing so that it can work precisely and actively. The piezoelectric crystals can work in the frequencies ranging from $20 \mathrm{KHz}$ to $15 \mathrm{MHz}$ The voltage passed through these devices develops the ultrasonic waves [23].

\section{RESULTS AND DISCUSSION}

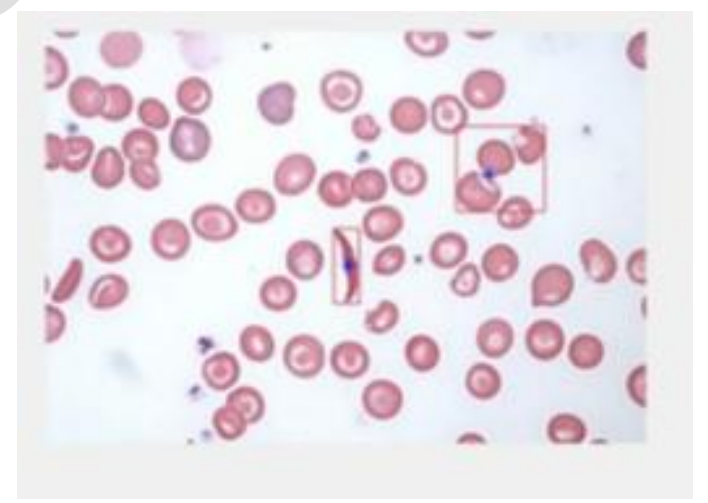

Fig (3): Image of Human blood consisting SCD 


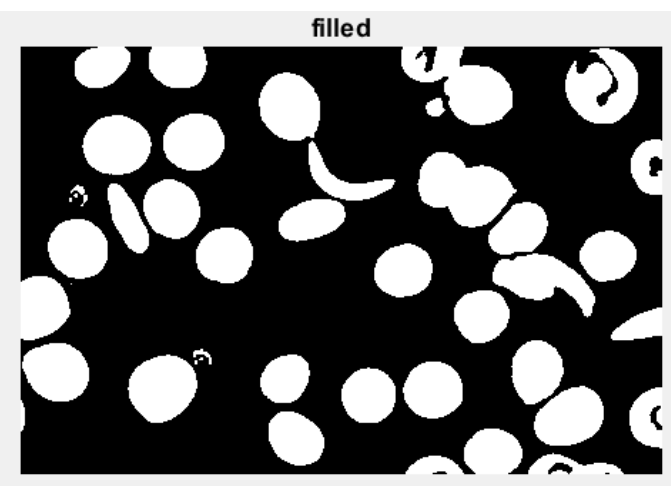

Fig (4): Grey Scaling the actual image.

In figure 3, human blood is collected and taken into observation. Ultrasonic image transduce can be used to take image of cell in micro level with the help of magnifying lens. Once the image is obtain, it can be grey scaled with the help of image filters [24]. The grey scaled image is shown in figure 4. As this process is done, the microprocessor reads the sickle shaped cell only.

The Box counting algorithm can be used to calculate the shape and size of the cell. This method is also used to detect face recognition techniques.

By reducing the size of the image grid we can calculate more area.

This Box counting or fractal Dimension methodshave various utility, consisting of for the face recognition the usage of the fractal code which extract the critical feature [25]. The method can be evolved in addition to recognize from components of a face in preference to the entire without a want for segmentation. The fractal analysis is probably a promising device for studying RBC clump [26].

There are presented strategies of capabilities assessment, and records visualization [23] to apprehend species of the tree based totally on the fractal measurement the use of boxcounting is the simple, top for classification feature and fast. The fractal dimension the use of field-counting is also used for the determination of the leaf vascular system of tree [27]. This paper proposed a way for recognition of the sickle cell inside the blood smear by doing the segmentation with the help of fractal dimension.

\section{CONCLUSION}

In this paper, we have discuss the various method which are used by medical centers and hospitals. Ultrasonic image transducer can be used for low cost and effective results in rural area to detect sickle cell patients. As compare to old technique this can be used. Digital image processing, box counting method and fractal dimension methods will enhance the quality of results to detect sickle cell in human body. This is quick, cost effective process that can give estimated value and can additionally reduce the methods projected earlier.

\section{REFERENCES}

[1]. Julie Ann Buford, "Sickle Cell Hemoglobin and Malaria: An Adaptive study of Natural Selection on an Infectious Disease", 18 Feb 2004.

[2]. Paunipagar PV, Pati SKB, Singh CM,Arya RC, "Sickle Cell Gene in Tribal Area of Rajnandgaon district of Chhattisgarh",Indian J. prev. Soc. Med. Vol. 37 No. 3 \& 4,2006.

[3]. J. Poomcokrak and C. Neatpisarnvanit, "Red Blood Cells Extraction and Counting", The 3rd International Symposium on Biomedical Engineering (ISBME 2008). 
[4].MagudeeswaranVeluchamy, KarthikeyanPerumal and ThirumuruganPonuchamy, "Feature Extraction and Classification of Blood Cells Using Artificial Neural Network", American Journal of Applied Sciences 9 (5): 615-619, 2012, ISSN 1546-9239.

[5]. SiddharthSekharBarpanda, "Use of Image Processing Techniques to Automatically Diagnose Sickle-Cell Anaemia Present in RBC Smear", National Institute of Technology (ODISHA), May-2013.

[6]. Daniel MaitethiaMemeu“A Rapid Malaria Diagnostic Method Based on Automatic Detection and Classification of Plasmodium Parasites in Stained Thin Blood Smear Images", University of Nairobi, March, 2014.

[7]. Aruna N.S. ,Hariharan S. "Edge Detection of Sickle Cells in Red Blood Cells",(IJCSIT) International Journal of Computer Science and Information Technologies, Vol. 5 (3), 2014,Pages 4140-4144, ISSN 0975-9646.

[8]. [10]. AthiraSreekumar, prof Ashok Bhattacharya, "Identification of Sickle cells from Microscopic Blood Smear Image Using image processing", International journal of Emerging Trends in Science and Technology, volume-01,Issue-05, Pages 783-787, July 2014, ISSN 2348-9480.

[9]. NasrulHumaimiMahmood and Muhammad AsrafMansor, "Red Blood Cells Estimation Using Hough Transform Technique", Signal \& Image Processing : An International Journal (SIPIJ) Vol.3, No.2, April 2012.

[10]. Manuel Gonzalez-Hidalgo,F.A.Guerero-pena ,S.Herold- Garcia, "Red Blood Cell Cluster Separation from Digital Images for use in Sickle Cell Disease", IEEE Journal of Biomedical and Health Informatics, JBHI.2014.2356402.

[11]. Philip Beaver and Stephanie M. Quirk(U.S Military Academy) Joseph P.Sattler (Army research lab) "Object Characterization in Grey Scale Imagery Using Fractal Dimension" U.S. Army Research laboratory, December 2015.

[12]. Nadia M.G. Al-Saidi, Arkan J. Mohammed Adil M. Ahmed, "Fuzzy Fractal Dimension Based on Escape Time Algorithm", Applied Mathematics Sciences, Vol. 8, 2014, no. 3, 117 129, Hikari ltd.

[13]. Ebrahimpour-Komleh, Hossein, Chandran, Vinod, \&Sridharan, Sridha“Face recognition using fractal codes". In Proceedings of International Conference on Image Processing 2001, IEEE, Thessaloniki, Greece.

[14]. Alina Rapa ,ServiliaOancea, DorinaCreanga, "Fractal dimensions in RBC", Turk J Vet AnimSci 29 , 2005, Pages 1247-1253.

[15]. Tomasz Les, MichałKruk,StanisławOsowski, "Objects classification using fractal dimension and shape based on leaves classification", WarsawUniveristy of Technology \& Life sciences.

[16] M. Bhatt1 \& S. Prabha, (Jan- June 2015), "Detection of Abnormal Blood CellsUsing Image Processing Techniques", IJEEE, Vol 07, Issue 01, PP.89-93.

[17] Deepika N. Patil\&Uday P. Khot, (September, 2015), "Image Processing Based Abnormal Blood Cells Detection," www.ijtra.com Special Issue 31, PP. 37-43.

[18] SiddharthBarpanda, (May-2013), "Use of Image Processing Techniques to Automatically Diagnose Sickle-Cell Anemia Present in Red Blood Cells Smear" Retrieved November 29, 2016 from http://ethesis.nitrkl.ac.in/5022/1/109EE0255.pdf.

[19] Image Processing Toolbox, Retrieved November 29, 2016 from https://www.mathworks.com/products/image/

[20] Jinping LI, Hongshan MU, Wei XU, (November 2013), "A Method of Using Digital Image Processing for Edge Detection of Red Blood Cells”, Sensors \& Transducers, Vol. 159, Issue 11, pp. 1-6. 
[21] Pandit, A., Kolhar, S., \&Patil, P. (2015). Survey on Automatic RBC Detection and Counting. International Journal of Advanced Research in Electrical,Electronics and Instrumentation Engineering, Vol 4, Issue 1, 128-131.

[22] Menika S, Amit B \& K. Uma, (March 2015), "Detection of Sickle Cell Anemia in Red Blood Cell: A", International Journal of Engineering and Applied Sciences (IJEAS) ISSN: 2394-3661, Volume-2, Issue-3,.

[23] Aruna N.S. \&Hariharan S, (2014) "Edge Detection of Sickle Cells in Red Blood Cells", (IJCSIT) International Journal of Computer Science and Information Technologies,ISSN:0975-9646, Vol. 5, Issue 3, 4140-4144.

[24] Mazalan, S. M., Mahmood, N. H., \&Razak, M. A. (2013). Automated Red Blood Cells Counting in Peripheral Blood Smear Image Using Circular Hough Transform. 2013 1st International Conference on Artificial Intelligence,Modelling and Simulation. doi:10.1109/aims.2013.59.

[25] I.A. Chintawar. Pravin N. Aishvarya M. Chetan K, (March 2016), "Detection of Sickle Cells using Image Processing", IJSTE - International Journal of Science Technology \& Engineering, Volume 2, Issue 09, ISSN (online): 2349-784X, .[26] Rakshit, P., \&Bhowmik, K. (2013). Detection of Abnormal Findings in Human

[26]RBC in Diagnosing Sickle Cell Anaemia Using Image Processing. Procedia Technology, 10, 28-36. doi:10.1016/j.protcy.2013.12.333.

[27] Shilpa K. \&R.K.Krishna, "Image Segmentation and Region Growing Algorithm", 